\title{
Enhancement of Mechanical Properties of Aluminum and 2124 Aluminum Alloy by the Addition of Quasicrystalline Phases
}

\author{
Witor Wolf ${ }^{\star *}$, Luis César Rodríguez Aliaga ${ }^{b}$, Dilermando Nagle Travessa ${ }^{c}$, Conrado Ramos Moreira \\ Afonso ${ }^{d}$, Claudemiro Bolfarinid, Claudio Shyinti Kiminamid, Walter José Botta ${ }^{d}$ \\ ${ }^{a}$ Graduate Program in Materials Science and Engineering, Federal University of São Carlos - \\ UFSCAR, Rod. Washington Luiz, Km 235, 13565-905, São Carlos, SP, Brazil \\ ${ }^{b}$ Polytechnic Institute, State University of Rio de Janeiro - UERJ, R. Bonfim 25, 28625-570, Nova \\ Friburgo, RJ, Brazil \\ ${ }^{c}$ Science and Technology Institute, Federal University of São Paulo - UNIFESP, R. Talim 330, 12231 - \\ 280, São José dos Campos, SP, Brazil \\ ${ }^{d}$ Department of Materials Engineering, Federal University of São Carlos - UFSCAR, Rod. Washington \\ Luiz, Km 235, 13565-905, São Carlos, SP, Brazil
}

Received: February 02, 2016; Revised: May 5, 2016; Accepted: August 5, 2016

\begin{abstract}
A structural and mechanical characterization of pure aluminum and $2124 \mathrm{~T} 6$ aluminum alloy reinforced with quasicrystalline phases of composition $\mathrm{Al}_{65} \mathrm{Cu}_{20} \mathrm{Fe}_{15}$ and $\mathrm{Al}_{70.5} \mathrm{Pd}_{21} \mathrm{Mn}_{8.5}$ (\%at.) were performed. The quasicrystalline phases were synthesized by arc melting and then milled to produce powder of the alloys, which were then mechanical mixed with the starting powders of aluminum and 2124 aluminum alloy. The composites were produced by hot extrusion of a mechanical mixture containing $20 \%$ (\%wt.) of the reinforcing phases on the metallic matrix. The structural characterization of the composites was carried out by X-ray diffraction, scanning electron microscopy and transmission electron microscopy. Mechanical characterization was carried out by Vickers hardness measurements and torsion tests at room temperature. The pure aluminum/quasicrystal composite showed the presence of the same phases from the starting powder mixture while for the 2124 aluminum alloy/ $\mathrm{Al}_{65} \mathrm{Cu}_{20} \mathrm{Fe}_{15}$ the quasicrystalline phase transformed to the tetragonal $\omega-\mathrm{Al}_{7} \mathrm{Cu}_{2} \mathrm{Fe}$ during the solution heat treatment. Mechanical strength of the composites presented a substantial increase in comparison to the original matrix metal. While the equivalent ultimate tensile strength of the $\mathrm{Al} /$ quasicrystal composites reached values up to $215 \mathrm{MPa}$ and Vickers hardness up to $60 \mathrm{HV}$, the 2124/quasicrystal composites reached values up to $670 \mathrm{MPa}$ and Vickers hardness up to $190 \mathrm{HV}$.
\end{abstract}

Keywords: Quasicrystals, Metal matrix composites, TEM, Aluminum alloys

\section{Introduction}

Since the discovery of quasicrystals by D. Shechtman ${ }^{1}$ many efforts have been made to understand the peculiar structure of these materials as well as their unusual combination of properties. The quasicrystalline structure presents crystallographic properties, which are not present for the crystalline structures, such as five, eight, ten and twelvefold rotational symmetry ${ }^{2}$. So far, there has been a great number of metallic systems that are reported to form quasicrystalline phases such as $\mathrm{Al}-\mathrm{Cu}-\mathrm{Fe}^{2}, \mathrm{Al}-\mathrm{Fe}-\mathrm{Cr}-\mathrm{TM}$ $(\mathrm{TM}=\mathrm{Ti}, \mathrm{V}, \mathrm{Nb}, \mathrm{Ta})^{3-5}, \mathrm{Al}-\mathrm{Co}^{6,7} \mathrm{Al}-\mathrm{Cu}-\mathrm{Fe}-\mathrm{Cr}^{8}, \mathrm{Al}-\mathrm{Co}-\mathrm{Ni}{ }^{9}, \mathrm{Al}-$ $\mathrm{Mn}^{1,10}$, among others. The atomic structure of these materials lead to unusual properties, as for instance, high hardness, brittleness and low thermal and electric conductivity in the case of aluminum-based alloys ${ }^{11}$.

In the $\mathrm{Al}-\mathrm{Cu}-\mathrm{Fe}$ system a great number of intermetallic phases are present around the quasicrystal phase composition,

\footnotetext{
* e-mail: witorw@gmail.com
}

such as $\lambda-\mathrm{Al}_{13} \mathrm{Fe}_{4}, \mathrm{Al}_{3} \mathrm{Fe}, \omega-\mathrm{Al}_{7} \mathrm{Cu}_{2} \mathrm{Fe}$ among others${ }^{2}$. The quasicrystalline phase in this system presents an icosahedral structure. There is also a cubic solid solution phase called $\beta-\mathrm{AlFe}(\mathrm{Cu})$, which is usually present when an ingot is fabricated within the quasicrystal compositional range ${ }^{2}$. Many of these phases are called approximants of the quasicrystalline phase due to their structure and properties, which are related ${ }^{12}$. In the Al-Pd-Mn system there is also formation of intermetallic phases around the quasicrystalline phases, which can present both the icosahedral and decagonal structures, depending on the chemical composition ${ }^{13}$. Both Al-Cu-Fe and Al-Pd-Mn quasicrystalline phases are thermodynamically stable ${ }^{2,14}$.

The brittleness presented by the quasicrystalline phases does not allow structural application in the bulk form. However, the use of quasicrystalline phase as a reinforcing phase on a ductile matrix can result in high strength alloys with good ductility. There are several studies on the literature about the fabrication of aluminum-based alloys with quasicrystalline reinforcing phases. Rapidly solidified alloys from the Al-Fe-Cr-TM (TM=TI, V, Nb, Ta) system, 
with right composition, can form quasicrystalline phases embedded in an aluminum matrix ${ }^{3,15}$ and the mechanical properties obtained are outstanding.

Powder metallurgy route can also be used for fabrication of quasicrystal composites, via hot pressing and hot extrusion of a powder mixture of aluminum and the quasicrystalline phase $^{16-19}$. However, so far, none of the reported work on the literature regarding $\mathrm{Al} /$ quasicrystal composites has been done with an aeronautic 2124 aluminum alloy and so the present work aims to show the influence of the quasicrystalline phase on the mechanical properties and on the quasicrystalline phase stability after the solution and aging heat treatment of the 2124 alloy. As a reference, pure Al-based composites reinforced with the same QC phases were also produced.

In both cases, two different quasicrystalline alloys $\left(\mathrm{Al}_{65} \mathrm{Cu}_{20} \mathrm{Fe}_{15}\right.$ and $\mathrm{Al}_{70.5} \mathrm{Pd}_{21} \mathrm{Mn}_{8.5}$ ) were fabricated and used to produce $\mathrm{Al} /$ quasicrystal and $2124 \mathrm{Al}$ /quasicrystal composites and so, the influence of the quasicrystalline alloy used on the mechanical properties and on the phase stability of the composite material was studied. The effect of reinforcing particle distribution on the yield strength was also analyzed in terms of the matrix ligament size $(\lambda)$ (which is a measurement of the average size of matrix regions constrained by the reinforcing phase) as proposed $\mathrm{in}^{20}$.

\section{Materials and Methods}

Quasicrystalline reinforcing powders of composition $\mathrm{Al}_{65} \mathrm{Cu}_{20} \mathrm{Fe}_{15}$ and $\mathrm{Al}_{70.5} \mathrm{Pd}_{21} \mathrm{Mn}_{8.5}$ were fabricated by arcmelting of high purity ( $>99.99 \%$ ) alloying elements and subsequently were mechanically milled for 30 minutes in a SPEX-type mill. Previously to the milling, the $\mathrm{Al}_{65} \mathrm{Cu}_{20} \mathrm{Fe}_{15}$ alloy was annealed at $700{ }^{\circ} \mathrm{C}$ for 3 hours in order to obtain the quasicrystalline phase as there were, as expected, a substantial amount of intermetallic phases which formed during the solidification. The $\mathrm{Al}_{70.5} \mathrm{Pd}_{21} \mathrm{Mn}_{8.5}$ alloy consisted mostly of the quasicrystalline phase and so it was not submitted to an annealing heat treatment. The quasicrystalline powders were then blended in a planetary ball mill for 5 hours with pure aluminum and 2124 aluminum alloy powders. Ball to powder ratio of 10:1 and milling velocity of $600 \mathrm{rpm}$ were used. The proportion of quasicrystalline phase on the blend was $20 \%$ in weight. The composites were then compacted by cold pressing and hot extruded at $420{ }^{\circ} \mathrm{C}$ with an extrusion ratio of 10:1 resulting in samples with 5 $\mathrm{mm}$ diameter. The extrusion conditions were chosen from previous report ${ }^{19}$. The composites fabricated with the 2124 aluminum alloy were submitted to a solution heat treatment at $490{ }^{\circ} \mathrm{C}$ for 1 hour followed by an aging heat treatment at $191{ }^{\circ} \mathrm{C}$ for 9 hours. The 2124 composites were heat treated in air and quenched in water. The quasicrystalline powders were analyzed by X-ray diffraction (XRD) in a Siemens $\mathrm{D} 5005 \mathrm{X}$-ray diffractometer using $\mathrm{Cu}-\mathrm{K} \alpha$ radiation. The composites were also analyzed by XRD and by scanning and transmission electron microscopy (SEM and TEM) using a Philips XL-30 FEG (SEM) and a TECNAI G2 F20 $200 \mathrm{kV}$ (TEM). The matrix ligament size $(\lambda)$ was measured using SEM images from the composites and by drawing 10 random lines on the microstructure of each composite and dividing the length measured by the number of intercepts caused by the presence of the reinforcing particles $(\mathrm{N})$ as it was performed in ${ }^{20}$. Image $\mathrm{J}$ software was used to measure the matrix ligament size $(\lambda)$. The mechanical properties of the extruded composites were evaluated by Vickers hardness using $1 \mathrm{kgf}$ and by torsion tests at room temperature. Torsion samples with $10 \mathrm{~mm}$ of length and $4 \mathrm{~mm}$ of diameter were used. From torsion tests results it was possible to calculate the equivalent tensile stress and elongation using the Von Mises distorted energy theory and so, the ultimate torsion strength and the shear deformation were expressed by means of equivalent ultimate tensile strength and equivalent deformation at rupture.

\section{Results and Discussion}

Figure 1 shows the XRD patterns of the annealed $\mathrm{Al}_{65} \mathrm{Cu}_{20} \mathrm{Fe}_{15}$ and $\mathrm{Al}_{70.5} \mathrm{Pd}_{21} \mathrm{Mn}_{8.5}$ alloys after high-energy ball milling, confirming the presence of the icosahedral quasicrystalline phase in both alloys as the major phase. A decagonal quasicrystalline phase can also be formed in the Al-Pd-Mn system ${ }^{13}$, however, for the $\mathrm{Al}_{70.5} \mathrm{Pd}_{21} \mathrm{Mn}_{8.5}$ composition only the icosahedral quasicrystalline phase was observed in the XRD pattern.

Figures 2 (a) to (d) show the XRD patterns of the composites with matrix of pure aluminum or 2124 aluminum alloy (Al/QC and 2124/QC). The composites fabricated with pure aluminum (Figures 2 (a) and 2 (b)) showed the presence of the original phases included in the starting powders, that is, aluminum fcc and icosahedral quasicrystalline phase. Therefore, no phase transformation took place during the processing steps, which included high-energy ball milling and hot extrusion.

Figures 3 (a) and (b) show TEM bright field images of the $\mathrm{Al} / \mathrm{AlCuFe}$ and $\mathrm{Al} / \mathrm{AlPdMn}$ composites, respectively, and, in the inserts, the selected area electron diffraction patterns (SAEDP) corresponding to the quasicrystalline phases. For both systems, the SAEDP show the five-fold rotational symmetry, confirming the icosahedral symmetry of the quasicrystalline phase, which is surrounded by the aluminum matrix.

Comparison of the XRD patterns from the composites $\mathrm{Al} / \mathrm{AlCuFe}$, Figure 2(a) and 2124/AlCuFe, (Figure 2(c)), indicates an important phase transformation that occurs after solution/ageing heat treatment. In the case of the 2124 alloy matrix reinforced by the $\mathrm{Al}-\mathrm{Cu}-\mathrm{Fe}$ quasicrystalline phase, the peaks of the icosahedral phase becomes very week and the $\omega-\mathrm{Al}_{7} \mathrm{Cu}_{2} \mathrm{Fe}$ phase can be clearly identified. Also, as 


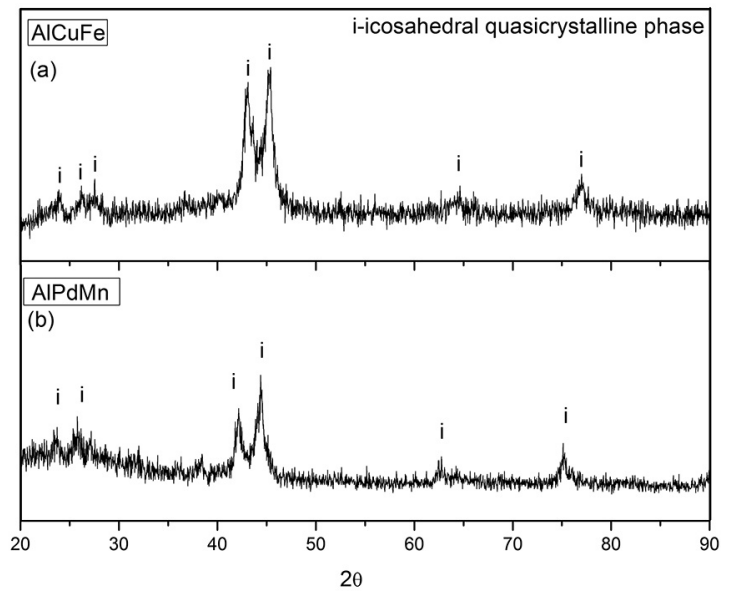

Figure 1: $\mathrm{XRD}$ patterns of the annealed $\mathrm{Al}_{65} \mathrm{Cu}_{20} \mathrm{Fe}_{15}$ and $\mathrm{Al}_{70.5} \mathrm{Pd}_{21} \mathrm{Mn}_{8.5}$ quasicrystalline reinforcing powders, in (a) and (b), respectively.

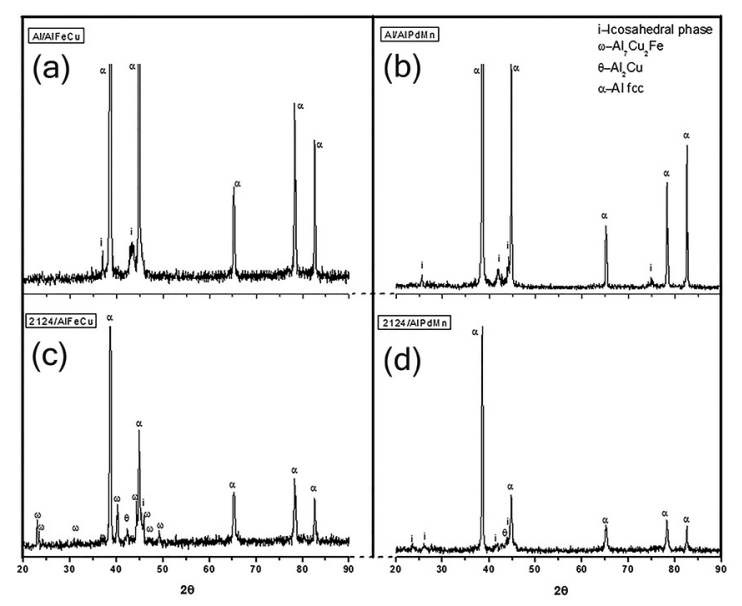

Figure 2: XRD patterns of the aluminum and 2124 aluminum alloy composites. (a) $\mathrm{Al} / \mathrm{AlCuFe}$. (b) $\mathrm{Al} / \mathrm{AlPdMn}$. (c) $2124 / \mathrm{AlCuFe}$. (d) 2124/AlPdMn.

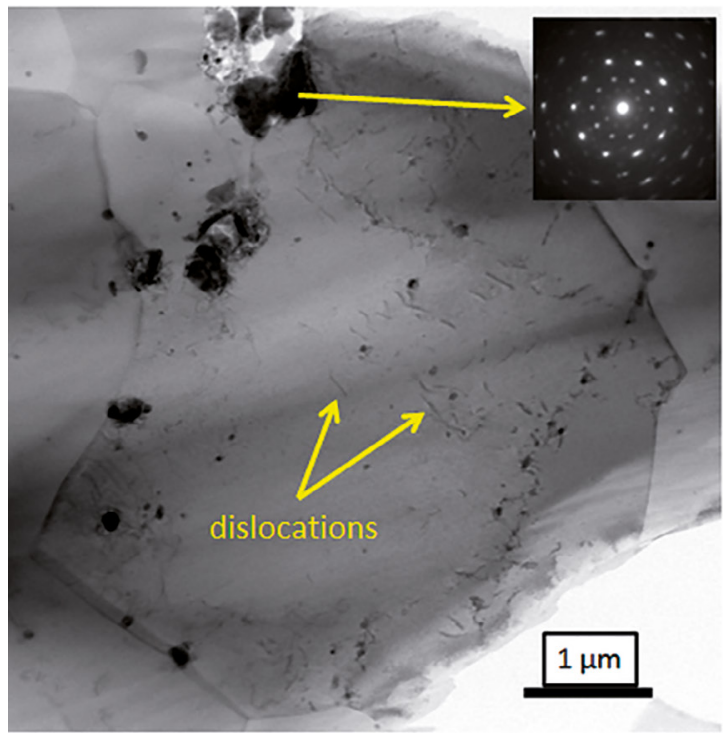

expected after aging of aluminum alloys from the $2 \mathrm{XXX}$ series the presence of $\mathrm{Al}_{2} \mathrm{Cu}$ is observed.

Figure 4 shows TEM bright field image of the 2124/ $\mathrm{AlCuFe}$ composite with selected area electron diffraction patterns of two particles from the reinforcing phase (one of them indicated on figure 4 (a)). The image in Figure 4a indicates that a refined microstructure of precipitates formed at the aging heat treatment and also a good dispersion of the reinforcing particles from the original quasicrystalline phase was obtained. Figures 4 (b) and (c) confirms the phase $\omega-\mathrm{Al}_{7} \mathrm{Cu}_{2} \mathrm{Fe}$ with diffraction patterns taken along the [111] and [311] zone axis, respectively. This phase is a tetragonal phase and belongs to the space group $\mathrm{P} 4 / \mathrm{mnc}$.

The Al-Cu-Fe phase diagram ${ }^{12}$ indicates that the phase $\omega-\mathrm{Al}_{7} \mathrm{Cu}_{2} \mathrm{Fe}$ forms as an intermediate phase between the quasicrystalline phase and the fcc aluminum. Consequently, the tetragonal phase is slightly richer in aluminum than the quasicrystalline phase. This reaction of icosahedral phase transforming into the tetragonal phase takes place during the solution heat treatment applied to the 2124 aluminum alloy. The same phenomena was observed by Ali et al. ${ }^{18}$ during heating of an aluminum matrix composite with $\mathrm{Al}-\mathrm{Cu}-\mathrm{Fe}$ quasicrystalline phase, the author observed a phase shift from the icosahedral to the tetragonal phase starting at $482{ }^{\circ} \mathrm{C}$. As the $2124 / \mathrm{AlCuFe}$ composite was submitted to solution heat treatment at 490 ${ }^{\circ} \mathrm{C}$ for 1 hour, the phase transformation observed was in fact, expected. This phase transformation (quasicrystal to $\omega-\mathrm{Al}_{7} \mathrm{Cu}_{2} \mathrm{Fe}$ ) results in an increase of the reinforcement volume because the $\omega-\mathrm{Al}_{7} \mathrm{Cu}_{2} \mathrm{Fe}$ phase has higher molar volume than the quasicrystalline phase ${ }^{18}$. This leads to a better bonding between matrix and reinforcing particles, which is in favor for the mechanical properties of the composite.

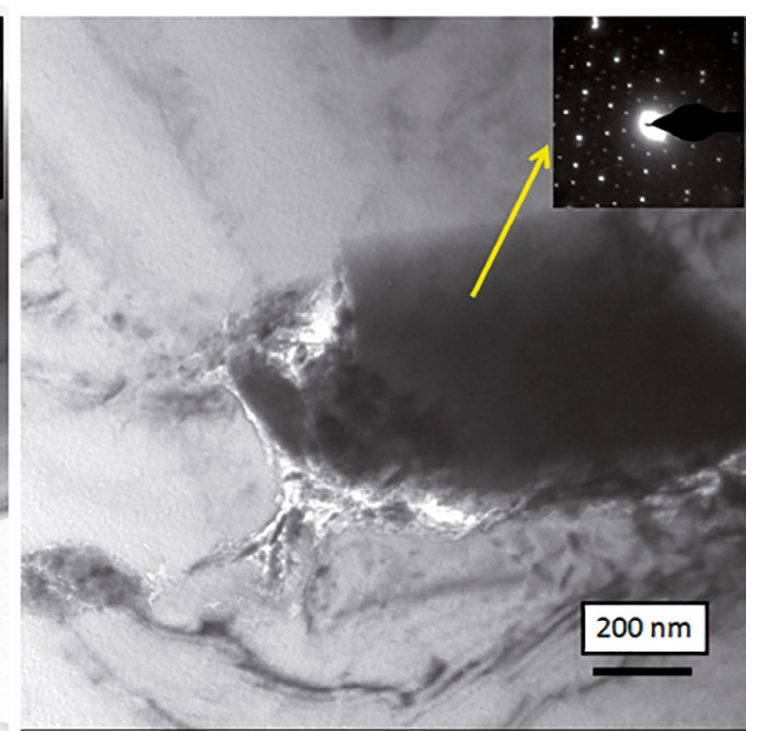

Figure 3: TEM bright field image with selected area electron diffraction pattern of the quasicrystalline phase showing the five-fold rotational symmetry.(a) Al/AlCuFe composite. (b) Al/AlPdMn composite. 


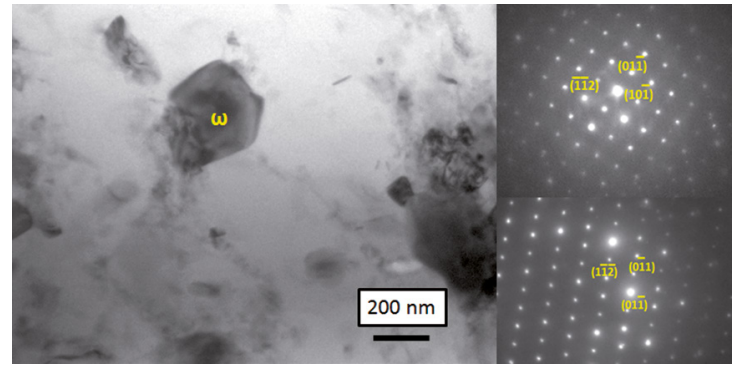

Figure 4: TEM bright field image (a) of the 2124/AlCuFe composite and two selected area diffraction patterns taken from the reinforcing phase (b) and (c).

The 2124/AlPdMn composite did not show the formation of any additional phase other than the $\mathrm{Al}_{2} \mathrm{Cu}$. The solubility of manganese in aluminum at this temperature is very limited and there is no solubility of palladium in aluminum ${ }^{21}$. Therefore, the low or none solubility of the quasicrystalline phase constituents in the aluminum matrix, can explain the remaining presence of the quasicrystalline phase on the 2124/ AlPdMn composite, even after the solution heat treatment.

Figure 5 (a)-(d) shows SEM micrographs of the composites. It is clear that the 2124 composites show a better dispersion of the reinforcing particles. The greater refinement observed for the reinforcing phases on the 2124 composites is related to the differences in the matrix strengths in pure aluminum and in 2124 alloy (the latter shows higher mechanical strength). A stronger matrix leads to a greater breakdown of the hard reinforcing phases, thus leading to a better dispersion of the second phase. The strengthening effect of the reinforcing particles in metal matrix composites are related basically to load bearing effect due to stress transfer from the matrix to the particles and the nucleation of dislocation lines in the matrix due to the presence of the reinforcement ${ }^{22}$. This last effect is showed in figure 3 (a) where it is possible to see interaction of the smallest particles with dislocations lines.

For composites with large amount of reinforcing particles ( $\geq 12 \%$ in volume) it has been reported that in addition to the strengthening effects mentioned above, the matrix ligament size $(\lambda)$ affects substantially the mechanical properties ${ }^{20}$. According to this model, the increase in the yield strength due to the presence of a reinforcing phase is:

$$
\Delta \sigma=\frac{k}{\sqrt{\lambda}}
$$

where, $\mathrm{k}$ is a strengthening constant. The matrix ligament size effect is similar to the strengthening by grain refinement because the matrix/particle interface can prevent dislocation movement ${ }^{20}$. Low values of $\lambda$ can be achieved with a good dispersion of the reinforcing phase and by reduction of the average particle size. In this sense, reducing the matrix ligament size leads to an increase of yield strength of the material similarly to the effect of grain size reduction predicted by the Hall-Petch relationship ${ }^{23}$. The model proposed in reference ${ }^{20}$ does not account for the precipitation hardening effect. In our results, the aging heat treatment leads very fine precipitation within the aluminum matrix, increasing the matrix strength. Thus, since the matrix ligament size $(\lambda)$ was not affected by the presence of the precipitates, the effect of the reinforcing phase was evaluated in comparison to the 2124, heat treated, base alloy ${ }^{24}$.

Table 1 shows the yield strength and the matrix ligament size of the composites. Ali et al. ${ }^{19}$ employed eq. (1) for $\mathrm{Al} /$ $\mathrm{Al}-\mathrm{Cu}-\mathrm{Fe}$ composites with the strengthening constant of 200 $\mathrm{MPa} . \mu \mathrm{m}^{1 / 2}$. This value was also used in the present work to
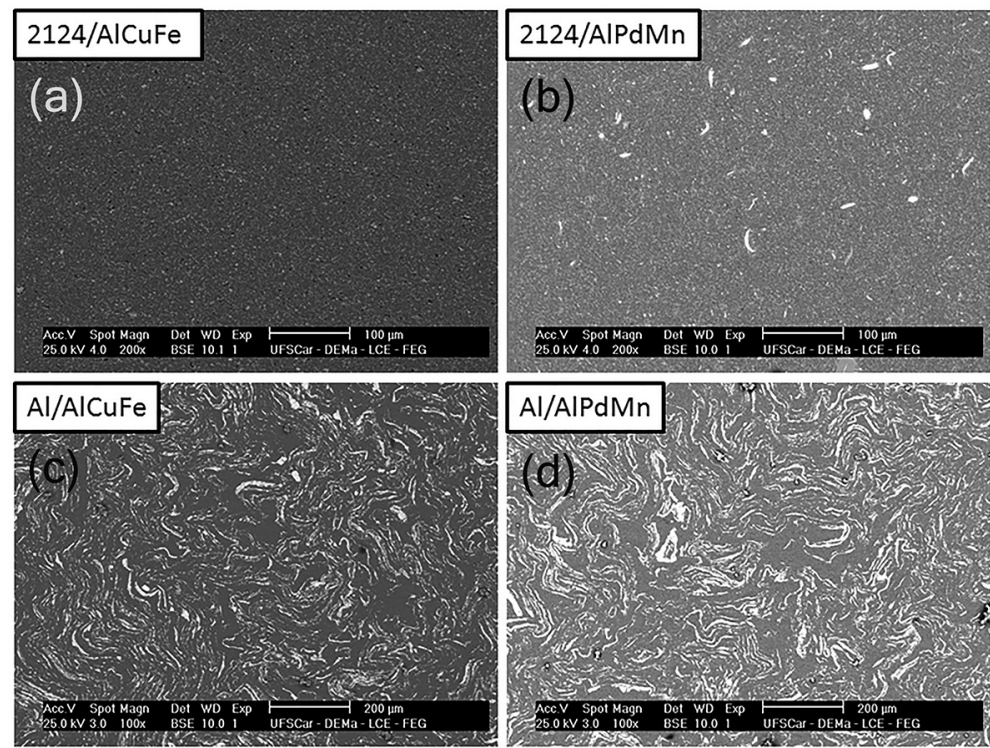

Figure 5: SEM images of the aluminum/quasicrystal and 2124 aluminum alloy/quasicrystal. (a) 2124/AlCuFe. (b) 2124/AlPdMn. (c) $\mathrm{Al} / \mathrm{AlCuFe}$. (d) Al/AlPdMn. 
Table 1: Equivalent Yield strength, matrix ligament size, predicted increase of yield strength using $k$ from reference ${ }^{19}$ and the real increase of yield strength presented by the composites.

\begin{tabular}{lcccc}
\hline Composite & eq. $\sigma_{\text {ys }}(\mathrm{MPa})$ & $\lambda(\mu \mathrm{m})$ & $\Delta \sigma$ predicted $^{19}\left(\mathrm{k}=200 \mathrm{MPa}^{\prime} \mu \mathrm{m}^{1 / 2}\right)(\mathrm{MPa})$ & $\Delta \sigma \mathrm{real}(\mathrm{MPa})$ \\
\hline $\mathrm{Al} / \mathrm{AlCuFe}$ & 155 & 14.14 & 53 & 42 \\
$\mathrm{Al} / \mathrm{AlPdMn}$ & 141 & 14.62 & 52 & 28 \\
$2124 / \mathrm{AlCuFe}$ & 561 & 1.29 & 176 & 168 \\
$2124 / \mathrm{AlPdMn}$ & 535 & 1.39 & 170 & 142 \\
\hline
\end{tabular}

predict the increase of the yield strength. The results are summarized in Table 1. A yield strength of $113 \mathrm{MPa}$ for pure aluminum extruded in similar conditions ${ }^{20}$ was used in the calculations to obtain the real increase of yield strength of the $\mathrm{Al}$ based composites. For the 2124 composites, the reference value used was $393 \mathrm{MPa}$ taken from reference ${ }^{24}$.

The predicted results of $\Delta \sigma$ are in good agreement with the experimental results for the $\mathrm{Al} / \mathrm{AlCuFe}$ and $2124 / \mathrm{AlCuFe}$ composites, presenting a good correspondence of the value of $\mathrm{k}=200 \mathrm{MPa} . \mu \mathrm{m}^{1 / 2}$ taken from ${ }^{19}$. However, the constant "k" used does not represent well the behavior of the Al/AlPdMn and 2124/AlPdMn. The constant " $\mathrm{k}$ " used was calculated from results obtained with the $\mathrm{AlCuFe}$ reinforcing particles in reference ${ }^{19}$. It would be expected that the value of the constant " $\mathrm{k}$ " would change for different reinforcing phases. For example, in reference ${ }^{20}$ for $\mathrm{Al}-\mathrm{Mg}$ intermetallic reinforcing phase, "k" used was $380 \mathrm{MPa} \cdot \mathrm{m}^{1 / 2}$. In this sense, a different value of " $\mathrm{k}$ " for the AlPdMn should exist and according to our results, it is lower than $200 \mathrm{MPa} \cdot \mathrm{m}^{1 / 2}$, which was used for the $\mathrm{AlCuFe}$ reinforcing phase.

Figure 6 shows the equivalent ultimate tensile strength, Vickers hardness and equivalent tensile strain obtained for the composites in torsion tests. The UTS observed for the $\mathrm{Al} / \mathrm{QC}$ composites reached values up to $215 \mathrm{MPa}$ and in the case of 2124 composites values up to $670 \mathrm{MPa}$ were obtained. This last result shows an important increase of the UTS of the 2124 composite. The heat treated 2124 alloy, according to ${ }^{24}$, has to present UTS greater than $455 \mathrm{MPa}$. The composites showed an increase close to $50 \%$ of the original alloy, which is already considered a high strength aluminum alloy. The ductility observed is within the specification ${ }^{24}$ for the 2124/AlPdMn and slightly lower for the 2124/AlCuFe. High values of Vickers hardness were also observed, being close to $190 \mathrm{HV}$ for the 2124 composites.

\section{Conclusions}

Metal matrix composites containing quasicrystalline phases as reinforcements were produced by powder metallurgy route.

Two matrix were used; pure $\mathrm{Al}$ and the $\mathrm{Al}$ alloy 2124, each of these matrix were reinforced with two different quasicrystalline phases, $\mathrm{Al}_{65} \mathrm{Cu}_{20} \mathrm{Fe}_{15}$ and $\mathrm{Al}_{70.5} \mathrm{Pd}_{21} \mathrm{Mn}_{8.5}$. The amount of reinforcing phase in all the composites was of $20 \%$ in weight.

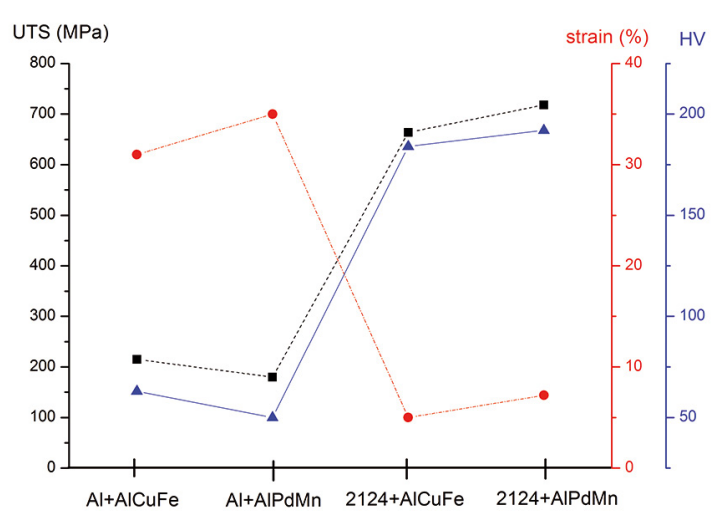

Figure 6: Mechanical properties obtained for the composites. Squares: equivalent ultimate tensile strength; triangles: Vickers hardness; circles: equivalent deformation at rupture.

The pure Al matrix composites presented the same phases from the starting powder blend, that is, fcc aluminum and icosahedral quasicrystalline phase.

A phase transformation was observed in the case of the $2124 \mathrm{Al}$ alloy matrix composite reinforced with the $\mathrm{AlCuFe}$ quasicrystalline phase. In this case, the QC phase shifted to the tetragonal $\omega-\mathrm{Al}_{7} \mathrm{Cu}_{2} \mathrm{Fe}$ due to aluminum enrichment within the quasicrystal during the solution heat treatment.

The mechanical strength of the composites were superior to the matrix material, especially for the 2124 aluminum alloy composites which showed significant increase on the UTS (455 to 670MPa) and on Vickers hardness in comparison to the base alloy.

\section{Acknowledgments}

The authors are grateful for the financial support granted by FAPESP (process n ${ }^{\circ}$ 2011/06497-9), CAPES and CNPq.

\section{References}

1. Shechtman D, Blech I, Gratias D, Cahn JW. Metallic Phase with Long-Range Orientational and No Translational Symmetry. Physical Review Letters. 1984;53(20):1951-1954.

2. Huttunen-Saarivirta E. Microstructure, fabrication and properties of quasicrystalline $\mathrm{Al}-\mathrm{Cu}-\mathrm{Fe}$ alloys: a review. Journal of Alloys and Compounds. 2004;363(1-2):154-178.

3. Galano M, Audebert F, Stone IC, Cantor B. Nanoquasicrystalline $\mathrm{Al}-\mathrm{Fe}-\mathrm{Cr}-\mathrm{based}$ alloys. Part I: Phase transformations. Acta Materialia. 2009;57(17):5107-5119. 
4. Galano M, Audebert F, García-Escorial A, Stone IC, Cantor B. Nanoquasicrystalline Al-Fe-Cr-based alloys. Part II. Mechanical properties. Acta Materialia. 2009;57(17):5120-5130.

5. Gargarella P, Vilar R, Almeida A, Kiminami CS, Rios CT, Bolfarini $\mathrm{C}$, Botta WJ. Laser remelting of $\mathrm{Al}_{91} \mathrm{Fe}_{4} \mathrm{Cr}_{3} \mathrm{Ti}_{2}$ quasicrystalline phase former alloy. Journal of Alloys and Compounds. 2010;495(2):646-649.

6. Grushko B, Holland-Moritz D, Bickmann K. Decagonal quasicrystals in Al-Co and ternary alloys containing $\mathrm{Cu}$ and Ni. Journal of Alloys and Compounds. 1996;236(1-2):243-252.

7. Schroers J, Holland-Moritz D, Herlach DM, Grushko B, Urban $\mathrm{K}$. Undercooling and solidification behaviour of a metastable decagonal quasicrystalline phase and crystalline phases in Al-Co. Materials Science and Engineering: A. 1997;226-228:990-994.

8. Sordelet D J, Widener SD, Tang Y, Besser MF. Characterization of a commercially produced $\mathrm{Al}-\mathrm{Cu}-\mathrm{Fe}-\mathrm{Cr}$ quasicrystalline coating. Materials Science and Engineering: A 2000;294-296:834-837.

9. Grushko B, Velikanova TY. Stable and metastable quasicrystals in Al-based alloy systems with transition metals. Journal of Alloys and Compounds. 2004;367(1-2):58-63.

10. Coury FG, Botta WJ, Bolfarini C, Kiminami CS, Kaufman MJ. Reassessment of the effects of Ce on quasicrystal formation and microstructural evolution in rapidly solidified A1-Mn alloys. Acta Materialia. 2015;98:221-228.

11. Dubois JM. Useful Quasicrystals. New Jersey: World Scientific Publishing; 2005. 482 p.

12. Dubois JM. Properties- and applications of quasicrystals and complex metallic alloys. Chemical Society Reviews. 2012;41:6760-6777.

13. Grushko B, Yurechko M, Tamura N. A contribution to the Al-Pd-Mn phase diagram. Journal of Alloys and Compounds. 1999;290(1-2):164-171.

14. Tsai AP, Inoue A, Yokoyama Y, Masumoto T. Stable Icosahedral $\mathrm{Al}-\mathrm{Pd}-\mathrm{Mn}$ and Al-Pd-Re Alloys. Materials Transactions, JIM. 1990;31(2):98-103.

15. Galano M, Audebert F, Cantor B, Stone I. Structural characterisation and stability of new nanoquasicrystalline Al-based alloys. Materials Science and Engineering: A. 2004;375-377:1206-1211.
16. Kaloshkin SD, Tcherdyntsev VV, Laptev AI, Stepashkin AA, Afonina EA, Pomadchik AL, et al. Structure and mechanical properties of mechanically alloyed $\mathrm{Al} / \mathrm{Al}-\mathrm{Cu}-\mathrm{Fe}$ composites. Journal of Materials Science. 2004;39(16):5399-5402.

17. Kaloshkin SD, Tcherdyntsev VV, Danilov VD. Preparation of $\mathrm{Al}-\mathrm{Cu}-\mathrm{Fe}$ quasicrystalline powdered alloys and related materials by mechanical activation. Crystallography Reports. 2007;52(6):953-965.

18. Ali F, Scudino S, Anwar MS, Shahid RN, Srivastava VC, Uhlenwinkel V, et al. Al-based metal matrix composites reinforced with $\mathrm{Al}-\mathrm{Cu}-\mathrm{Fe}$ quasicrystalline particles: Strengthening by interfacial reaction. Journal of Alloys and Compounds. 2014;607:274-279.

19. Ali F, Scudino S, Liu G, Srivastava VC, Mukhopadhyay NK, Samadi Khoshkhoo M, et al. Modeling the strengthening effect of $\mathrm{Al}-\mathrm{Cu}-\mathrm{Fe}$ quasicrystalline particles in Al-based metal matrix composites. Journal of Alloys and Compounds. 2012;536(Suppl 1):S130-S133.

20. Scudino S, Liu G, Sakaliyska M, Surreddi KB, Eckert J. Powder metallurgy of Al-based metal matrix composites reinforced with $\beta-\mathrm{Al}_{3} \mathrm{Mg}_{2}$ intermetallic particles: Analysis and modeling of mechanical properties. Acta Materialia. 2009;57(15):4529-4538.

21. ASM International. ASM Handbook, Volume 3: Alloy Phase Diagrams. Materials Park: ASM International; 1992.

22. Chaubey AK, Scudino S, Mukhopadhyay NK, Samadi Khoshkhoo M, Mishra BK, Eckert J. Effect of particle dispersion on the mechanical behavior of Al-based metal matrix composites reinforced with nanocrystalline Al-Ca intermetallics. Journal of Alloys and Compounds. 2012;536(Supp1 1):S134-S137.

23. Hall EO. The Deformation and Ageing of Mild Steel: III Discussion of Results. Proceedings of the Physical Society. Section B. 1951;64(9):747-753.

24. SAE International. AMS4101 E: Aluminum Alloy, Plate, 4.4Cu1.5Mg - 0.6Mn (2124-T851), Solution Heat Treated, Streached and Precipitation Heat Treated. SAE International; 2012. Available from: $<$ https://www.sae.org/works/documentHome. do? comtID=TEAAMSD\&docID=AMS4101E\&inputPage $=\mathrm{dO}$ cDeTaIlS $>$. Access in: 10/8/2016. 